\title{
Comments on "3-aminopropyltriethoxysilane functionalized nanoscale zero-valent iron for the removal of dyes from aqueous solution"
}

\author{
Yuh-Shan Ho \\ Asia University, Water Research Centre, Taichung 41354, Taiwan, e-mail: ysho@asia.edu.tw
}

Recently, Zhang et al. published the paper entitled "3-aminopropyltriethoxysilane functionalized nanoscale zero-valent iron for the removal of dyes from aqueous solution"1. In section of Adsorption mechanism, authors stated that "The Langmuir equation was found to fit well with the adsorption isotherms. The Langmuir equation was adopted in this study to calculate the kinetic data." In fact, Langmuir equation is a well known adsorption isotherm. In the same section, authors also stated that "In Langmuir equation, the adsorption kinetic rate was often calculated using the following equation: the pseudo-first-order adsorption kinetic equation (2) and the pseudo-second-order adsorption kinetic equation (3)" without any citations. Equation (3), the Lagergren rate equation presented in 1898, is a first order model ${ }^{2}$ but not a pseudo-second-order adsorption kinetic equation. In order to distinguish a kinetic equation based on the adsorption capacity of a solid from one based on the concentration of a solution, Lagergren's first-order rate equation has been called pseudo-first order model since $1998^{3,4}$. The pseudo-first-order adsorption kinetic equation (2) was also reported in $1998^{3}$. Again, the equation (2) is pseudo-second-order kinetic model. A review of second-order models for adsorption systems has also been presented in another paper ${ }^{5}$.

It is clear that both Eqs. (2) and (3) are the pseudo- second order and the pseudo-first order kinetic models but are not the pseudo-first-order adsorption kinetic equation (2) and the pseudo-second-order adsorption kinetic equation (3).

Accuracy of citations and quotations are very important for the transmission of scientific knowledge. In my view, Zhang et al. ${ }^{1}$ should have cited the original paper for the kinetic models, and thereby, provided more accurate information about the kinetic expression employed in the article.

\section{LITERATURE CITED}

1. Zhang, J.Y., Liu, Q.Y., Ding, Y.J. \& Bei, Y.L. (2011). 3-aminopropyltriethoxysilane functionalized nanoscale zero-valent iron for the removal of dyes from aqueous solution. Pol. J. Chem. Technol., 13 (2), 35-39. DOI: 10.2478/v10026-011-0021-x.

2. Lagergren, S. (1898). Zur theorie der sogenannten adsorption gelöster stoffe. K. Sven. Vetenskapsakad. Handl., 24 (4), 1-39.

3. Ho, Y.S. \& McKay, G. (1998). Sorption of dye from aqueous solution by peat. Chem. Eng. J., 70 (2), 115-124.

4. Ho, Y.S. (2004). Citation review of Lagergren kinetic rate equation on adsorption reactions. Scientometrics, 59 (1), 171-177. DOI: 10.1023/B:SCIE.0000013305.99473.cf.

5. Ho, Y.S. (2006). Review of second-order models for adsorption systems. J. Hazard. Mater., 136 (3), 681-689. DOI:10.1016/j.jhazmat.2005.12.043. 